\title{
The impact of induction therapy on morbidity and operative mortality after resection of primary lung cancer
}

\author{
Nathaniel R. Evans III, MD, ${ }^{\mathrm{a}}$ Shuang Li, MS, ${ }^{\mathrm{b}}$ Cameron D. Wright, MD, ${ }^{\mathrm{a}}$ Mark S. Allen, MD, ${ }^{\mathrm{c}}$ and \\ Henning A. Gaissert, MD
}

Objective: Use and operative results of neoadjuvant therapy before major elective resection for primary lung cancer were examined in the Society of Thoracic Surgeons General Thoracic Surgical Database.

\begin{abstract}
Methods: Lobectomy and pneumonectomy for primary lung cancer were identified in 12,201 patients between January 2002 and June 2008. After excluding procedures for missing clinical staging or end points; institutions with more than $10 \%$ missing data for clinical stage, discharge mortality, or length of stay; and patients treated with chemotherapy or radiation for unrelated disease, there remained 5376 resections. Study end points were discharge mortality, length of stay more than 14 days, and major morbidity. Multivariate analysis using propensity scores stratified into quintiles measured the effect of induction therapy.
\end{abstract}

Results: In 525 of 5376 procedures $(9.8 \%)$, chemotherapy $(\mathrm{n}=153)$, radiotherapy (23), or chemoradiotherapy (349) preceded resection. Compared with resection only, patients receiving induction therapy were younger and had fewer comorbidities, more reoperative surgery, and higher rates of pneumonectomy. Clinical IIIA-N2 disease was treated with induction therapy in only 203 of 397 patients $(51.1 \%)$. Propensity-adjusted rates detected no difference in discharge mortality, prolonged length of stay, or a composite of major morbidity for patients receiving induction therapy. Similar results were obtained in a logistic regression model (discharge mortality $P=.9883$; prolonged hospital stay $P=.9710$; major morbidity $P=.9678$ ).

Conclusion: Less than $10 \%$ of all major lung resections for primary carcinoma and just more than half of all resections for clinical stage IIIA-N2 disease are preceded by neoadjuvant chemotherapy or radiation. This study does not support concerns over excessive operative risk of induction therapy. (J Thorac Cardiovasc Surg 2010;139:991-6)

Earn CME credits at

http://cme.ctsnetjournals.org

Supplemental material is available online.

Distant metastasis is the most common site of treatment failure after surgical resection for lung cancer. Neoadjuvant chemotherapy aims to reduce distant and, with the addition of thoracic radiotherapy in selected patients, locoregional failure. Preoperative chemotherapy has been suggested as feasible and safe in the surgical treatment of non-small

\footnotetext{
From the Division of Thoracic Surgery, ${ }^{\text {a }}$ Massachusetts General Hospital, Boston, Mass; Duke Clinical Research Institute, ${ }^{\mathrm{b}}$ Duke University, Durham, NC; and Division of Thoracic Surgery, ${ }^{\mathrm{c}}$ Mayo Clinic, Rochester, Minn.

Disclosures: None.

Presented at the Annual Meeting of the Western Thoracic Surgical Association, Banff, AB, Canada, June 24-27, 2009.

Received for publication June 26, 2009; revisions received Oct 15, 2009; accepted for publication Nov 4, 2009.

Address for reprints: Henning A. Gaissert, MD, Massachusetts General Hospital, Blake 1570, Fruit Street, Boston, MA 02114 (E-mail: hgaissert@partners.org). $0022-5223 / \$ 36.00$

Copyright (c) 2010 by The American Association for Thoracic Surgery doi:10.1016/j.jtcvs.2009.11.070
}

cell lung cancer, although concerns linger about the operative mortality of pneumonectomy. ${ }^{1}$ Controversy remains as to whether patients receiving preoperative therapy are at greater risk of complications or death as a result, whereas there is agreement that these patients require careful selection of their candidacy for additional therapy. ${ }^{1-3}$

The Society of Thoracic Surgeons (STS) General Thoracic Surgery Database (GTSD) was queried to investigate the effect of induction therapy on operative mortality and morbidity. We compared patients receiving preoperative chemotherapy or radiation with those who did not to evaluate the impact of induction therapy on short-term outcomes.

\section{MATERIALS AND METHODS}

Major lung resections for primary pulmonary malignancy were collected from the STS GTSD between January 1, 2002, and June 30, 2008. This prospective database includes patient demographics, medical history, surgical procedure details, staging, and short-term outcomes. Data were submitted voluntarily from 112 participating institutions and 463 surgeons during a period of significant database expansion using 2 versions of a data-collection form (http://www.sts.org/sections/stsnationaldatabase/datamanagers/genera thoracicdb/datacollection/index.html). In accordance with the Health Insurance Portability and Accountability Act of 1996, data were stored and maintained after annual or biannual harvest at the Duke Clinical Research Institute, where data completeness and compliance were checked. Incomplete data were returned to each institution for amendment. The institutional review boards of all participating institutions agreed to the use of data for quality improvement research. 


\author{
Abbreviations and Acronyms \\ $\mathrm{CI}=$ confidence interval \\ $\mathrm{FEV}_{1}=$ forced expiratory volume in 1 second \\ $\mathrm{FVC}=$ forced vital capacity \\ GTSD $=$ General Thoracic Surgery Database \\ PLOS $=$ prolonged length of stay \\ STS $=$ Society of Thoracic Surgeons
}

\section{Patient Population}

Entry criteria for this study were elective major lung resections, lobectomy, sleeve lobectomy, bilobectomy, or pneumonectomy performed for primary lung malignancy. Data on timing of neoadjuvant therapy relative to resection were not collected; however, because intervals of more than 3 months between chemotherapy or radiotherapy and surgical therapy for this diagnosis are uncommon, we assumed that therapy before resection had the purpose of induction. The assignment of clinical stage is critical to the indication for neoadjuvant therapy and influences the type of resection; however, this variable was not routinely collected by several of the database participants. For this reason, we excluded from our study all procedures done at institutions with less than $90 \%$ completeness for clinical staging. Among 29 database participants reporting more than 100 patients, 15 had missing clinical stage data in more than $10 \%$ of procedures; the participant with the largest number of entries reported clinical stage in only $10 \%$ of procedures. The consort diagram (Figure 1) displays patient population and excluded operations. Given the present database maturity and the low rates of 30-day or hospital mortality, prolonged length of stay (PLOS), and composite rates of morbidity, we combined patients receiving either chemotherapy or radiation or both into the induction group. The characteristics of the resultant patient population are reported in Table 1.

\section{Descriptive and Outcome Variables}

Preoperative risk factors, procedures, and postoperative events are defined by the STS GTSD. We examined 3 outcomes: discharge mortality, hospital stay more than 14 days, and a composite of major postoperative events. Discharge mortality was defined as occurring during the same hospitalization. PLOS greater than 14 days was found to be a surrogate for operative risk in a recent study of the STS GTSD. ${ }^{4}$ The composite of events included major postoperative complications (pneumonia, initial vent support $>48$ hours, reintubation, adult respiratory distress syndrome, tracheostomy, empyema, sepsis, bronchopleural fistula, myocardial infarction, deep vein thrombosis, bleeding requiring reoperation, and new central neurologic event).

\section{Handling of Missing Variables}

Model covariates with high rates of missing data were percent of predicted forced expiratory volume in 1 second $\left(\mathrm{FEV}_{1} ; 10.9 \%\right.$ missing), forced vital capacity (FVC; $18.7 \%$ missing), and body mass index $(8.15 \%$ missing). The remaining covariates were missing less than $5 \%$. For variables missing more than $10 \%$, an indicator for "missing" was included in the model. This strategy was used for $\mathrm{FEV}_{1}$ and FVC. For body mass index, missing data were imputed to the gender-specific median of non-missing values. For other continuous variables, the missing value was imputed to the overall median. Finally, for categoric variables, the missing value was imputed to the most common value.

\section{Statistical Analysis}

Summary statistics included percentages for categoric variables and medians for continuous variables. The Pearson chi-square test was used for comparing all categoric variables, and the Wilcoxon rank-sum test was used for comparing all the continuous or ordinal variables.
Propensity score stratification was used to adjust for differences in comorbidities, functional status, clinical stage, operative procedure, and operative approach. Logistic regression estimated the probability of undergoing resection with preoperative induction therapy. Covariates in this logistic model to estimate propensity score were age, body mass index, gender, race, $\mathrm{FEV}_{1}$ predicted, $\mathrm{FVC}$ predicted, tobacco use, time since last cigarette, pack years, hypertension, steroid use, congestive heart failure, coronary artery disease, peripheral vascular disease, cerebrovascular disease, diabetes mellitus, renal insufficiency, thoracic reoperation, clinical stage, American Society of Anesthesiology class, Zubrod score, type of procedure, and operative approach. Although we considered an earlier report from the STS GTSD on carbon monoxide diffusion capacity as a predictor of pulmonary complications, ${ }^{5}$ diffusion capacity of the lung for carbon monoxide was excluded from the multivariate analysis because the rate of missing data was high $(27.6 \%)$ and it was nonsignificant in the univariate analysis of unadjusted rates. Before propensity stratification, 32 of 52 covariates were significantly different between the groups with and without induction therapy. By using propensity scoring, resections were stratified in 5 strata; only 3 covariates, $\mathrm{FEV}_{1}$ predicted, $\mathrm{FVC}$ predicted, and clinical T1-3N2, remained significantly different after stratification. Tables E1 to E3 show the observed event rates along with $95 \%$ confidence interval (CI) of study end points (discharge mortality, PLOS, and the composite of major complications) by 5 subgroups based on propensity quintiles.

We used a multivariate logistic regression model to evaluate the association between induction therapy and our study end points adjusting for propensity strata. The variables offered to this multivariate model were treatment (induction therapy), propensity stratum, included interaction terms of treatment and stratum, and 3 covariates that remained significantly different after stratification. These 3 covariates were dichotomous indicator variables of missing of FEV predicted, missing of FVC predicted, and clinical stage: T1,2,3-N2.

All $P$ values were calculated by comparing only non-missing values. The Bonferroni correction was applied to the 21 postoperative events listed in Table 2, and the significance level was established as $.05 / 21=.00238$. Otherwise, the significance level was assessed at the .05 alpha level. All analyses were conducted using SAS 8.2 or SAS 9.2 (SAS Institute Inc, Cary, NC).

\section{RESULTS}

Of 5376 operations in the study group, 4851 were resections without and 525 with $(9.8 \%)$ preoperative therapy, the latter consisting of chemotherapy $(\mathrm{n}=153)$, radiotherapy (23), or chemoradiotherapy (349). The characteristics of the resection only and induction groups are compared in Table 1. Patients receiving induction were younger, more likely of Hispanic or Asian race, less likely recent smokers, more symptomatic, and more commonly in American Society of Anesthesiology class III. Induction patients had a higher FVC and a lower rate of hypertension, diabetes, coronary artery disease, and congestive heart failure. Resections after induction were furthermore 3 times as likely as thoracic reoperations $(10.3 \%$ vs $3.5 \%, P<.0001)$.

Induction therapy was applied in less than $10 \%$ of all resections: in 3.1\% (118/3790) of stage I disease, 17.6\% (108/ $613)$ of stage II disease, $49.3 \%$ (220/446) of stage IIIA disease, and $29.9 \%$ (46/154) of stage IIIB disease. Of 397 resections for clinical IIIA-N2 disease, $203(51.1 \%)$ were preceded by neoadjuvant therapy. Concurrent mediastinoscopy was performed in 14\% (56/397) of these procedures. In the induction therapy group with clinical N2, $80 \%$ 
Elective, Anatomic Lung resections for primary lung cancer in Adults: 12,930 operations

\section{Exclusions:}

135- Unrelated Chemo or Radiation 195- Clinical M1

399- Approach only Laparoscopy, laparotomy, or subxyphoid

12,201 remaining operations

xclusions:

6584 - Participant with poor quality data (60 sites excluded)

241 - Missing clinical stage, discharge mortality, or length of stay

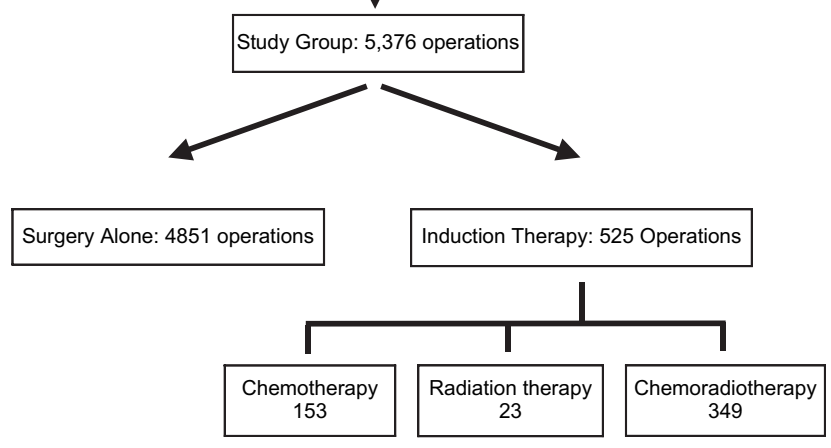

FIGURE 1. Consort diagram describing the exclusion criteria and resultant study population.

received combined chemoradiotherapy. Figure 2 depicts the treatment strategies in patients with stage II and III disease. Induction therapy preceded resection in only a minority of procedures for clinical stage II disease and less than half of all patients with stage III disease. As shown in Table 3, induction therapy was associated with higher rates of pneumonectomy, sleeve, and bilobectomy, as well as a preference for thoracotomy over thoracoscopy. The institution-specific separation of treatment strategies as shown in Figure E1 shows no preference for either resection only or multimodality therapy in centers with more than 5 resections. Clinical and pathologic N2 were widely divergent, as detailed in Table E4. Only $50 \%$ of resections without neoadjuvant therapy for clinical $\mathrm{T} 1-3 \mathrm{~N} 2$ disease were determined to have pathologic $\mathrm{N} 2$, whereas $42 \%$ receiving induction had retained $\mathrm{N} 2$ status in the final specimen.

Table 2 shows the univariate analysis of postoperative events. Patients in the induction group were more likely to require bronchoscopy for atelectasis and had higher rates of wound infection, recurrent laryngeal nerve injury, and either intra- or postoperative blood transfusions. The rate of bronchopleural fistula was approximately 3-fold higher; this difference was not significant in a comparison limited to clinical IIIA-N2 tumors. There was no difference in the rate of pneumonia, empyema, sepsis, or cardiovascular com- plications. There was no significant difference in the 30-day mortality or discharge mortality. Neither median nor mean length of stay was longer in the induction group (resection only vs induction, 6.84 vs 6.85 days; $P=.0551$ ), and there was no significant difference in the rate of PLOS $(7.2 \%$ in the resection only group and $8.2 \%$ in the induction group, $P=.311$ ). Morbidity as a composite of major pulmonary and cardiovascular complications showed no significant increase in the group of patients treated with preoperative chemotherapy or radiation.

Propensity-adjusted mortality rates were $1.71 \%(0.61 \%$ $2.82 \%$ ) for patients with induction therapy versus $1.67 \%$ $(1.31 \%-2.03 \%)$ for patients without induction therapy (difference $0.69 \% ; 95 \% \mathrm{CI},-3.53 \%$ to $4.90 \% ; P=.63$ ). Results were similar after including treatment (induction therapy), propensity stratum, interaction of treatment and propensity stratum, dichotomous indicator variables for missing $\mathrm{FEV}_{1}$ predicted, missing FVC predicted, and clinical stage IIIA(N2) in a logistic regression model $(P=$ .9883). For the end point length of stay greater than 14 days, the propensity-adjusted occurrence rate was $5.90 \%$ $(3.89 \%-7.92 \%)$ for patients with induction and $6.89 \%$ $(6.17 \%-7.60 \%)$ for patients without induction therapy (difference $-0.99 \% ; 95 \% \mathrm{CI},-4.79 \%$ to $2.81 \% ; P=.21)$. The logistic regression model showed no significant prolongation of stay after resections following induction therapy $(P$ $=.9710$ ). For the end point composite of major morbidity, the propensity-adjusted rate was $10.5 \%(7.86 \%-13.1 \%)$ for induction therapy and $9.21 \%(8.40 \%-10.0 \%)$ for resection alone (difference $-1.36 \% ; 95 \% \mathrm{CI},-4.69 \%$ to $1.97 \%$; $P=.31)$. The logistic regression model resulted in a similar outcome $(P=.9678)$. Risk-adjusted analysis did not detect a difference in discharge mortality, PLOS, or major morbidity for patients receiving induction therapy.

\section{DISCUSSION}

In an era when the benefits of postoperative adjuvant chemotherapy have become firmly established, a survey of major lung resection for cancer in the STS GTSD finds a low rate of neoadjuvant therapy, even for clinical stages with high distant and regional failure rates, and low operative risk whether or not induction therapy is administered. Although neoadjuvant therapy is well tolerated, it is not widely used for lung cancer among STS database participants. As shown in a previous report from the STS GTSD, ${ }^{6}$ the operative results of patients in the GTSD compare favorably to those reported in other large databases. This difference may be related to the higher level of training and experience in the surgeons participating in the GTSD. The voluntary structure of this database may allow for selective reporting and restrict generalization from this study to the wider thoracic surgical practice in North America; however, we do not expect a higher rate of neoadjuvant therapy in other multi-institutional thoracic databases. 
TABLE 1. Patient characteristics and comorbidities

\begin{tabular}{|c|c|c|c|}
\hline & $\begin{array}{l}\text { Resection } \\
N=4851\end{array}$ & $\begin{array}{l}\text { Induction therapy } \\
\qquad \mathbf{N}=\mathbf{5 2 5}\end{array}$ & $P$ value \\
\hline Age (median) & $68 y$ & 63 y & $<.0001$ \\
\hline \multicolumn{4}{|l|}{ Gender } \\
\hline Male & $49.52 \%$ & $49.90 \%$ & .8655 \\
\hline Race & & & .0119 \\
\hline Caucasian & $85.16 \%$ & $85.71 \%$ & \\
\hline Black & $8.70 \%$ & $6.10 \%$ & \\
\hline Hispanic & $1.63 \%$ & $2.48 \%$ & \\
\hline Asian & $1.92 \%$ & $2.29 \%$ & \\
\hline Native American & $0.02 \%$ & $0.19 \%$ & \\
\hline Missing/other/mixed & $2.58 \%$ & $3.23 \%$ & \\
\hline Cigarette use & $96.27 \%$ & $95.87 \%$ & .7882 \\
\hline Missing & $0.05 \%$ & $0.21 \%$ & \\
\hline Pack y (median) & 40 & 40 & .8307 \\
\hline Missing & $2.21 \%$ & $1.51 \%$ & \\
\hline Time since last cigarette & & & $<.0001$ \\
\hline $0-14 \mathrm{~d}$ & $22.90 \%$ & $19.05 \%$ & \\
\hline $14 \mathrm{~d}$ to $1 \mathrm{mo}$ & $4.76 \%$ & $3.24 \%$ & \\
\hline $1-12 \mathrm{mo}$ & $9.92 \%$ & $24.38 \%$ & \\
\hline$>12 \mathrm{mo}$ & $47.99 \%$ & $42.86 \%$ & \\
\hline Missing & $1.22 \%$ & $0.76 \%$ & \\
\hline Zubrod score & & & .0004 \\
\hline 0 & $46.28 \%$ & $38.10 \%$ & \\
\hline 1 & $44.26 \%$ & $46.48 \%$ & \\
\hline 2 & $4.97 \%$ & $7.43 \%$ & \\
\hline 3 & $0.66 \%$ & $1.14 \%$ & \\
\hline 4 & $0.02 \%$ & $0.19 \%$ & \\
\hline Missing & $3.81 \%$ & $6.67 \%$ & \\
\hline ASA category & & & .0019 \\
\hline $\mathrm{I}$ & $3.15 \%$ & $0.57 \%$ & \\
\hline II & $19.85 \%$ & $14.86 \%$ & \\
\hline III & $60.85 \%$ & $67.62 \%$ & \\
\hline IV-V & $11.67 \%$ & $11.62 \%$ & \\
\hline Missing & $4.41 \%$ & $5.33 \%$ & \\
\hline Body mass index (median) & 26.42 & 25.88 & .0540 \\
\hline Missing & $7.73 \%$ & $12.00 \%$ & \\
\hline \multicolumn{4}{|l|}{ PFTs (mean of $\%$ predicted) } \\
\hline FVC & $86.23 \%$ & $88.56 \%$ & .0118 \\
\hline Missing & $18.52 \%$ & $20.57 \%$ & \\
\hline $\mathrm{FEV}_{1}$ & $79.59 \%$ & $80.94 \%$ & .3196 \\
\hline Missing & $11.21 \%$ & $8.00 \%$ & \\
\hline DLCO & $73.52 \%$ & $71.93 \%$ & .1266 \\
\hline Missing & $28.53 \%$ & $19.24 \%$ & \\
\hline \multicolumn{4}{|l|}{ Comorbidities: } \\
\hline Hypertension & $57.14 \%$ & $37.52 \%$ & $<.0001$ \\
\hline Missing & $0.14 \%$ & $0.57 \%$ & \\
\hline Steroid use & $3.38 \%$ & $2.86 \%$ & .5321 \\
\hline Missing & $0.68 \%$ & $0.95 \%$ & \\
\hline Congestive heart failure & $3.17 \%$ & $1.52 \%$ & .0358 \\
\hline Missing & $0.68 \%$ & $0.76 \%$ & \\
\hline Coronary artery disease & $21.71 \%$ & $14.86 \%$ & .0003 \\
\hline Missing & $0.52 \%$ & $0.95 \%$ & \\
\hline Peripheral vascular disease & $9.83 \%$ & $4.95 \%$ & .0003 \\
\hline Missing & $0.56 \%$ & $0.76 \%$ & \\
\hline Cerebrovascular event & $11.86 \%$ & $12.00 \%$ & .2317 \\
\hline Missing & $1.67 \%$ & $1.14 \%$ & \\
\hline
\end{tabular}

TABLE 1. Continued

\begin{tabular}{lccr}
\hline & Resection & Induction therapy \\
& $\mathbf{N}=\mathbf{4 8 5 1}$ & $\mathbf{N}=\mathbf{5 2 5}$ & $\boldsymbol{P}$ value \\
\hline Diabetes & $\mathbf{1 4 . 7 4} \%$ & $\mathbf{9 . 7 1} \%$ & $\mathbf{. 0 0 1 7}$ \\
Missing & $0.02 \%$ & $0.00 \%$ & \\
Renal insufficiency & & & .1507 \\
Creatinine $>2$ & $2.37 \%$ & $1.71 \%$ & \\
Dialysis & $0.54 \%$ & $0.00 \%$ & \\
Missing & $0.39 \%$ & $0.19 \%$ & \\
Thoracic reoperation & $\mathbf{3 . 4 6} \%$ & $\mathbf{1 0 . 2 9} \%$ & $<. \mathbf{0 0 0 1}$ \\
Missing & $0.56 \%$ & $0.00 \%$ & \\
\hline ASA, American Society of Anesthesiology; $P F T$, pulmonary function test; $F V C$, forced \\
vital capacity; $F E V_{l}$, forced expiratory volume in 1 second; $D L C O$, carbon monoxide \\
diffusing capacity. Variables in bold font denote a significant difference between the \\
groups $(P<.05)$.
\end{tabular}

The role of neoadjuvant therapy in resectable lung cancer remains controversial, although small randomized trials demonstrated a survival benefit ${ }^{7,8}$ and a meta-analysis concurred. ${ }^{9}$ Other studies failed to confirm improved

TABLE 2. Postoperative events and outcomes in resection and induction groups

\begin{tabular}{|c|c|c|c|}
\hline Postoperative event & $\begin{array}{c}\text { Resection } \\
(\mathbf{N}=\mathbf{4 8 5 1}) \\
\text { No. of resections } \\
(\%)\end{array}$ & $\begin{array}{c}\text { Induction therapy } \\
(\mathbf{N}=\mathbf{5 2 5}) \\
\text { No. of resections } \\
(\%)\end{array}$ & $\begin{array}{c}P \\
\text { value }\end{array}$ \\
\hline Bronchoscopy & $162(3.34 \%)$ & $33(6.29 \%)$ & .0033 \\
\hline $\begin{array}{l}\text { Mechanical ventilation } \\
>48 \mathrm{~h}\end{array}$ & $35(0.72 \%)$ & $3(0.57 \%)$ & .5711 \\
\hline Reintubation & $186(3.83 \%)$ & $22(4.19 \%)$ & .9470 \\
\hline Tracheostomy & $62(1.28 \%)$ & $7(1.33 \%)$ & .8759 \\
\hline ARDS & $68(1.40 \%)$ & $9(1.71 \%)$ & .7793 \\
\hline Pneumonia & $212(4.37 \%)$ & $25(4.76 \%)$ & .9331 \\
\hline Empyema & $23(0.47 \%)$ & $2(0.38 \%)$ & .6587 \\
\hline Sepsis & $35(0.72 \%)$ & $1(0.19 \%)$ & .1206 \\
\hline Wound infection & $12(0.25 \%)$ & $7(1.33 \%)$ & $.0002 *$ \\
\hline Bronchopleural fistula & $17(0.35 \%)$ & $5(0.95 \%)$ & .0673 \\
\hline $\begin{array}{l}\text { Recurrent laryngeal } \\
\text { nerve injury }\end{array}$ & $21(0.43 \%)$ & $10(1.90 \%)$ & $<.0001 *$ \\
\hline Atrial arrhythmia & $558(11.5 \%)$ & $61(11.62 \%)$ & .4127 \\
\hline Myocardial infarction & $21(0.43 \%)$ & $2(0.38 \%)$ & .7522 \\
\hline Cerebrovascular event & $33(0.68 \%)$ & $4(0.76 \%)$ & .9852 \\
\hline $\begin{array}{l}\text { Deep venous } \\
\text { thrombosis }\end{array}$ & $22(0.45 \%)$ & $1(0.19 \%)$ & .3209 \\
\hline $\begin{array}{c}\text { Blood transfusion } \\
\text { Postoperative } \\
\text { outcomes: }\end{array}$ & $384(7.92 \%)$ & $93(17.71 \%)$ & $<.0001 *$ \\
\hline 30-d mortality & $89(1.83 \%)$ & $12(2.29 \%)$ & .4687 \\
\hline Discharge mortality & $81(1.67 \%)$ & $9(1.71 \%)$ & .9398 \\
\hline $\begin{array}{l}\text { Median length } \\
\text { of stay (d) }\end{array}$ & $5 \mathrm{SD} 6.23$ & $5 \mathrm{SD} 5.76$ & .0551 \\
\hline Length of stay $>14 \mathrm{~d}$ & $334(6.89 \%)$ & $31(5.90 \%)$ & .3963 \\
\hline $\begin{array}{l}\text { Composite of major } \\
\text { morbidity }\end{array}$ & $447(9.21 \%)$ & $55(10.5 \%)$ & .3347 \\
\hline
\end{tabular}




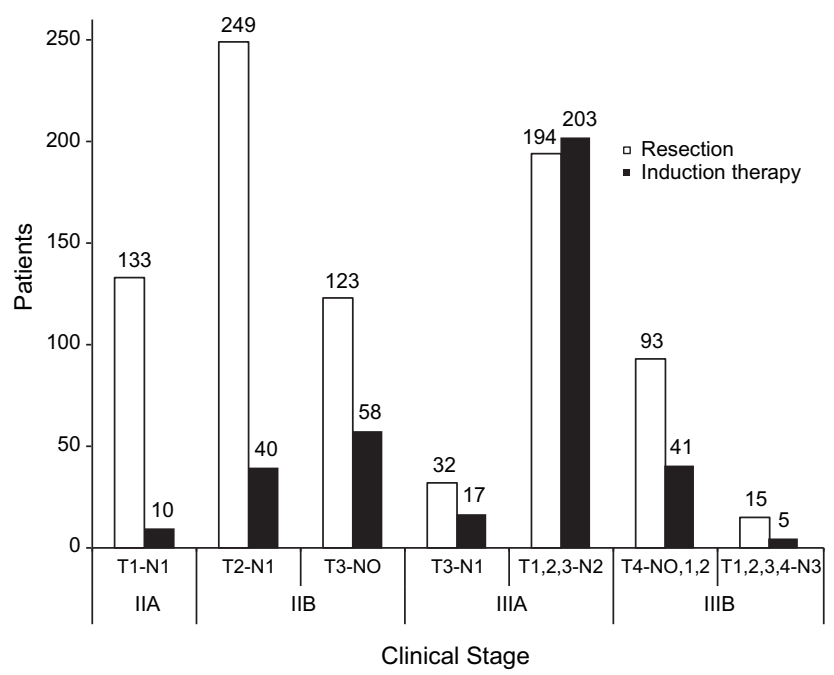

FIGURE 2. Treatment strategies in patients with clinical stage II and III disease.

survival, ${ }^{10,11}$ whereas individual institutions ${ }^{1,12}$ and multiinstitutional, prospective randomized studies ${ }^{13,14}$ reported increased risks of pneumonectomy after neoadjuvant therapy. Thus, a cautious attitude is appropriate toward induction therapy in stages that are not locally advanced. However, in stage IIIA, systemic disease poses a far greater threat even after complete resection; thus, neoadjuvant therapy should offer its greatest potential gain in this setting as acknowledged in clinical guidelines published by the American College of Chest Physicians in 2003. ${ }^{15}$ The observation that surgical resection is the first treatment of approximately half of all preoperatively recognized stage IIIA lung cancers is therefore surprising. A difference in the relative frequency of pathologic N2 status is expected for clinical N2 disease treated or not with induction; the effect of downstaging by chemoradiation, however, would be expected to exceed the difference of $8.2 \%$ noted in Table E4. The infrequent use of neoadjuvant therapy in IIIA-N2 disease in this study does not seem to relate to surgical vol- ume; there was no correlation between the number of patients with IIIA-N2 treated per participant site and the rate of induction therapy. The frequency of preoperative chemotherapy or radiation may have been underestimated if information on treatment delivered outside the participating center was unavailable and the respective data fields were left unchecked. Clinical staging inaccuracies were observed, but their impact on the use of neoadjuvant therapy is uncertain.

Among patients selected for resection by surgeons participating in the STS GTSD, preoperative chemotherapy and combined chemoradiotherapy were well tolerated. The differences in age, comorbid conditions, and lung function seen in the univariate analysis of preoperative variables between resection and multimodality therapy suggests that candidates were selected for neoadjuvant therapy and that this selection was successful in limiting operative death, major morbidity, and differences in length of hospital stay. However, the unadjusted rates of certain postoperative events were increased after induction therapy; bronchopleural fistula, for example, was approximately 3 times as common (albeit still rare). Thus, induction therapy may be associated with specific nonlethal operative risks. Because these data originate from a recently inaugurated database with limited, but growing participation, they may not be representative of selection standards in North American institutions treating lung cancer.

\section{Study Limitations}

There are important limitations to our study. The STS GTSD is unaudited; thus data entry and important variables, among them clinical stage, discharge mortality, and postoperative events, have not been checked for accuracy. The database is not designed to record treatment other than surgical resection and did not provide intention-to-treat analysis of patients treated with neoadjuvant therapy but not proceeding to resection. The operative mortality for induction with cisplatin and etoposide plus concurrent thoracic radiotherapy in the Southwestern Oncology Group study 8805, for example,

TABLE 3. Extent of resection and surgical approach for resection and induction procedures

\begin{tabular}{|c|c|c|c|c|c|}
\hline Extent of resection & \multicolumn{2}{|c|}{$\begin{array}{l}\text { Resection }(\mathrm{N}=4851) \\
\text { No. of resections }(\%)\end{array}$} & \multicolumn{2}{|c|}{$\begin{array}{c}\text { Induction therapy }(\mathrm{N}=525) \\
\text { No. of resections }(\%)\end{array}$} & $\frac{\boldsymbol{P} \text { value }}{<.0001}$ \\
\hline Lobectomy & 4299 & $(88.62 \%)$ & 399 & $(76.00 \%)$ & \\
\hline Sleeve lobectomy & 90 & $(1.86 \%)$ & 27 & $(5.14 \%)$ & \\
\hline Bilobectomy & 201 & $(4.14 \%)$ & 22 & $(4.19 \%)$ & \\
\hline Pneumonectomy, standard & 199 & $(4.10 \%)$ & 60 & $(11.43 \%)$ & \\
\hline $\begin{array}{l}\text { Pneumonectomy, } \\
\text { intrapericardial }\end{array}$ & 62 & $(1.28 \%)$ & 17 & $(3.24 \%)$ & \\
\hline Surgical approach & & & & & $<.0001$ \\
\hline Thoracotomy & 3289 & $(67.80 \%)$ & 458 & $(87.24 \%)$ & \\
\hline Thoracoscopy & 1438 & $(29.64 \%)$ & 56 & $(10.67 \%)$ & \\
\hline Other & 124 & $(2.56 \%)$ & 11 & $(2.10 \%)$ & \\
\hline
\end{tabular}


was $5.5 \%$, but the overall treatment-related mortality was $10 \% .{ }^{13}$ Details about the regimens of chemotherapy or radiation, or completeness of therapy that may expose differences in the implementation of induction therapy among participating centers were unavailable. Our criteria for exclusion of database participants led to loss of large numbers of procedures and may have selectively excluded qualitatively different patients or procedures; we considered a comparison of included and excluded procedures, but the amount of missing data would prevent a meaningful comparison. Finally, the conclusions of this study rest on accurate clinical staging. Although we found major discrepancies between clinical and pathologic staging in N2 disease, these differences remain unexplained and are difficult to resolve after data submission. A surgeon-initiated mandatory protocol for clinical staging before resection did not exist previously to address the unacceptably high rate of missing clinical staging. Medicare's 2009 Physician Quality Reporting Initiative, however, contains the recording of clinical staging before treatment for lung cancer (http://www.cms.hhs.gov/PQRI/Downloads/2009_PQRI_ MeasuresList_030409.pdf). This reporting requirement was added at the suggestion of the STS and should reduce the missing data problem for clinical staging. The STS GTSD has also recently defined more stringent data quality criteria for submission.

\section{CONCLUSIONS}

The STS GTSD presents a potentially powerful way to address clinical questions for which clinical trials have not yet been or may never be designed. Many STS surgeons may be skeptical of the efficacy of induction therapy for IIIA disease or fearful of excessive postoperative morbidity. We cannot answer the first question, but our study suggests there is not excessive morbidity after induction therapy. Prospectively collected data from multiple centers can be a robust tool to evaluate clinical questions. As the GTSD continues to grow both in procedures and number of participants with further refinement of collected variables, its usefulness as a research tool is expected to increase.

\section{References}

1. Martin J, Ginsberg RJ, Abolhoda A, Bains MS, Downey RJ, Korst RJ, et al. Morbidity and mortality after neoadjuvant therapy for lung cancer: the risks of right pneumonectomy. Ann Thorac Surg. 2001;72:1149-54.

2. Roberts JR, Eustis C, Devore R, Carbone D, Choy H, Johnson D. Induction chemotherapy increases perioperative complications in patients undergoing resection for non-small cell lung cancer. Ann Thorac Surg. 2001;72:885-8.

3. Venuta F, Anile M, Diso D, Ibrahim M, De Giacomo T, Rolla M, et al. Operative complications and early mortality after induction therapy for lung cancer. Eur J Cardiothorac Surg. 2007;31:714-7.

4. Wright CD, Gaissert HA, Grab JD, O'Brien SM, Peterson ED, Allen MS. Predictors of prolonged length of stay after lobectomy for lung cancer: a Society of Thoracic Surgeons General Thoracic Surgery Database risk-adjustment model. Ann Thorac Surg. 2008;85:1857-65.

5. Ferguson MK, Gaissert HA, Grab JD, Sheng S. Pulmonary complications after lung resection in the absence of chronic obstructive pulmonary disease-the predictive role of diffusing capacity. $J$ Thorac Cardiovasc Surg. 2009;138: 1297-302. Epub 2009 Sep 26.

6. Boffa DJ, Allen MS, Grab JD, Gaissert HA, Harpole DH, Wright CD. Data from The Society of Thoracic Surgeons General Thoracic Surgery database: the surgical management of primary lung tumors. J Thorac Cardiovasc Surg. 2008;135: 247-54.

7. Rosell R, Gomez-Codina J, Camps C, Javier Sanchez J, Maestre J, Padilla J, et al. Preresectional chemotherapy in stage IIIA non-small-cell lung cancer: a 7-year assessment of a randomized controlled trial. Lung Cancer. 1999;26:7-14.

8. Roth JA, Atkinson EN, Fossella F, Komaki R, Bernadette Ryan M, Putnam JB Jr, et al. Long-term follow-up of patients enrolled in a randomized trial comparing perioperative chemotherapy and surgery with surgery alone in resectable stage IIIA non-small-cell lung cancer. Lung Cancer. 1998;21:1-6.

9. Berghmans T, Paesmans M, Meert AP, Mascaux C, Lothaire P, Lafitte JJ, et al. Survival improvement in resectable non-small cell lung cancer with (neo)adjuvant chemotherapy: results of a meta-analysis of the literature. Lung Cancer. 2005;49:13-23.

10. Depierre A, Milleron B, Moro-Sibilot D, Chevret S, Quoix E, Lebeau B, et al. Preoperative chemotherapy followed by surgery compared with primary surgery in resectable stage I (except T1N0), II, and IIIa non-small-cell lung cancer. J Clin Oncol. 2002;20:247-53.

11. Mattson KV, Abratt RP, ten Velde G, Krofta K. Docetaxel as neoadjuvant therapy for radically treatable stage III non-small-cell lung cancer: a multinational randomised phase III study. Ann Oncol. 2003;14:116-22.

12. Doddoli C, Barlesi F, Trousse D, Robitail S, Yena S, Astoul P, et al. One hundred consecutive pneumonectomies after induction therapy for non-small cell lung cancer: an uncertain balance between risks and benefits. J Thorac Cardiovasc Surg. 2005;130:416-25.

13. Albain KS, Rusch VW, Crowley JJ, Rice TW, Turrisi AT 3rd, Weick JK, et al. Concurrent cisplatin/etoposide plus chest radiotherapy followed by surgery for stages IIIA (N2) and IIIB non-small-cell lung cancer: mature results of Southwest Oncology Group phase II study 8805. J Clin Oncol. 1995;13:1880-92.

14. Albain KS, Scott CB, Rusch VR. Phase III comparison of concurrent chemotherapy plus radiotherapy $(\mathrm{CT} / \mathrm{RT})$ and $\mathrm{CT} / \mathrm{RT}$ followed by surgical resection for stage IIIA (pN2) non-small cell lung cancer (NSCLC): initial results from intergroup trial 0139 (RTOG 93-09). Proc Am Soc Clin Oncol. 2003;22:621.

15. Robinson LA, Wagner H Jr, Ruckdeschel JC. Treatment of stage IIIA non-small cell lung cancer. Chest. 2003;123:202S-20S. 
Initial Treatment Modality in Clinical IIIA-N2 patients by participant site (sites with $\geq 5$ resections)

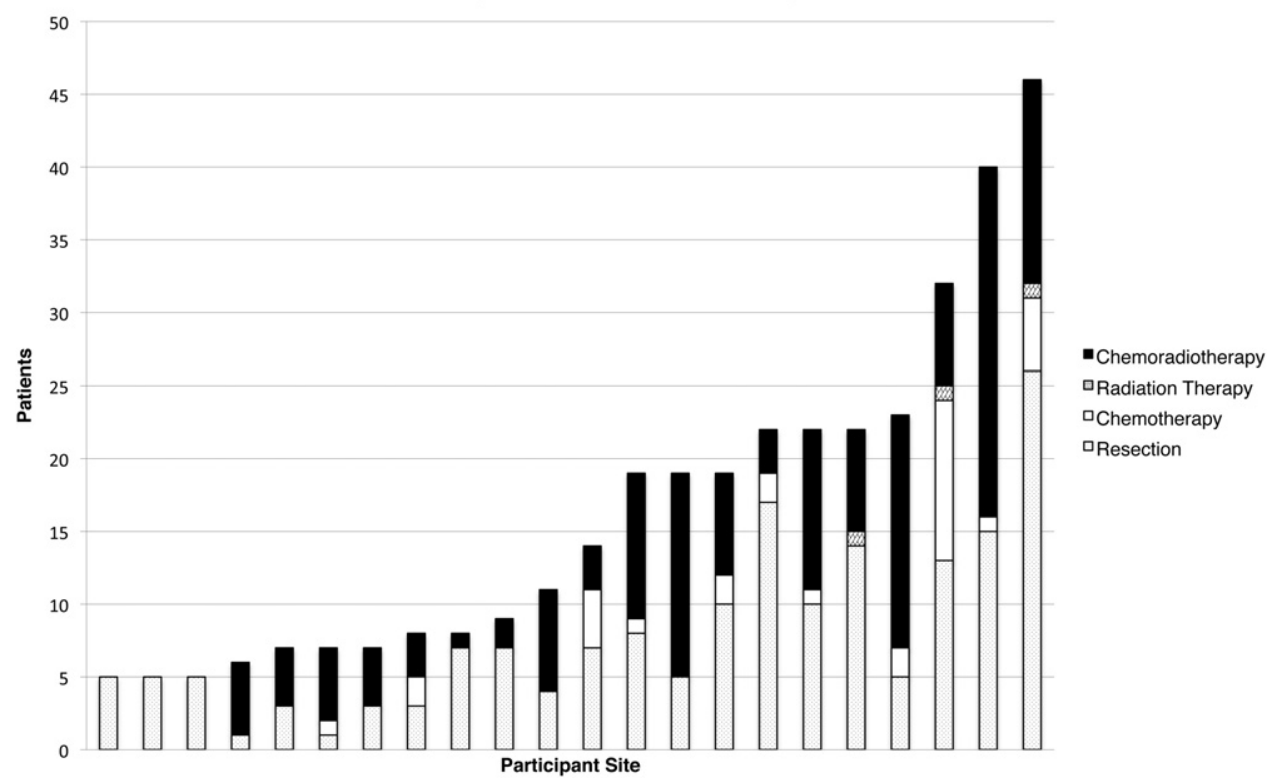

FIGURE E1. Initial treatment modalities in clinical T1-3N2 patients by participant site at sites with more than T1-3N2 resections.

TABLE E1. Discharge mortality rate by propensity score quintiles

\begin{tabular}{|c|c|c|c|c|}
\hline & \multicolumn{2}{|c|}{ Resection } & \multicolumn{2}{|c|}{ Induction therapy } \\
\hline & $\mathbf{N}$ & Mortality rate $(95 \%$ CI $)$ & $\mathbf{N}$ & Mortality rate $(95 \% \mathrm{CI})$ \\
\hline Quintile 1 & 1065 & $1.69 \%(0.92 \%-2.46 \%)$ & 10 & $0 \%(0 \%-0 \%)$ \\
\hline Quintile 2 & 1054 & $1.71 \%(0.93 \%-2.49 \%)$ & 21 & $4.76 \%(0 \%-13.87 \%)$ \\
\hline Quintile 3 & 1043 & $1.92 \%(1.09 \%-2.75 \%)$ & 33 & $3.03 \%(0 \%-8.88 \%)$ \\
\hline Quintile 4 & 997 & $1.60 \%(0.82 \%-2.38 \%)$ & 78 & $2.56 \%(0 \%-6.07 \%)$ \\
\hline Quintile 5 & 692 & $1.30 \%(0.46 \%-2.14 \%)$ & 383 & $1.31 \%(0.17 \%-2.44 \%)$ \\
\hline
\end{tabular}

CI, Confidence interval.

TABLE E2. Hospital stay greater than 14 days by propensity score quintiles

\begin{tabular}{lcccc}
\hline & \multicolumn{2}{c}{ Resection } & \multicolumn{2}{c}{ Induction therapy } \\
\cline { 2 - 4 } & $\mathbf{N}$ & PLOS $>\mathbf{1 4}$ d rate $\mathbf{( 9 5} \% \mathbf{C I})$ & $\mathbf{N}$ & PLOS $>\mathbf{1 4} \mathbf{d}$ rate $(\mathbf{9 5} \% \mathbf{C I})$ \\
\hline Quintile 1 & 1065 & $6.10 \%(4.67 \%-7.54 \%)$ & 10 & $0 \%(0 \%-0 \%)$ \\
Quintile 2 & 1054 & $5.88 \%(4.46 \%-7.30 \%)$ & 21 & $9.52 \%(0 \%-22.08 \%)$ \\
Quintile 3 & 1043 & $6.14 \%(4.68 \%-7.59 \%)$ & 33 & $6.06 \%(0 \%-14.20 \%)$ \\
Quintile 4 & 997 & $7.32 \%(5.71 \%-8.94 \%)$ & 78 & $7.69 \%(1.78 \%-13.61 \%)$ \\
Quintile 5 & 692 & $10.12 \%(7.87 \%-12.36 \%)$ & 383 & $5.48 \%(3.20 \%-7.76 \%)$ \\
\hline
\end{tabular}

PLOS, Prolonged length of stay; $C I$, confidence interval. 
TABLE E3. Major morbidity rate by propensity score quintiles

\begin{tabular}{|c|c|c|c|c|}
\hline & \multicolumn{2}{|c|}{ Resection } & \multicolumn{2}{|c|}{ Induction therapy } \\
\hline & $\mathbf{N}$ & Morbidity rate $(\mathbf{9 5} \% \mathrm{CI})$ & $\mathbf{N}$ & Morbidity rate $(95 \% \mathrm{CI})$ \\
\hline Quintile 1 & 1065 & $8.45 \%(6.78 \%-10.12 \%)$ & 10 & $0 \%(0.00 \%-0.00 \%)$ \\
\hline Quintile 2 & 1054 & $7.21 \%(5.65 \%-8.77 \%)$ & 21 & $14.29 \%(0.00 \%-29.25 \%)$ \\
\hline Quintile 3 & 1043 & $9.97 \%(8.15 \%-11.79 \%)$ & 33 & $6.06 \%(0.00 \%-14.20 \%)$ \\
\hline Quintile 4 & 997 & $10.63 \%(8.72 \%-12.55 \%)$ & 78 & $10.26 \%(3.52 \%-16.99 \%)$ \\
\hline Quintile 5 & 692 & $10.26 \%(8.00 \%-12.52 \%)$ & 383 & $10.97 \%(7.84 \%-14.10 \%)$ \\
\hline
\end{tabular}

CI, Confidence interval.

TABLE E4. Pathologic nodal status of patients with clinical T1-3, N2

\begin{tabular}{lcccc}
\hline $\begin{array}{c}\text { Pathologic } \\
\text { N-status }\end{array}$ & \multicolumn{2}{c}{$\begin{array}{c}\text { Resection }(\mathbf{N}=\mathbf{1 9 4}) \\
\text { No. of resections (\%) }\end{array}$} & \multicolumn{2}{c}{$\begin{array}{c}\text { Induction therapy }(\mathbf{N}=\mathbf{2 0 3}) \\
\text { No. of resections (\%) }\end{array}$} \\
\hline N0 & 61 & $(31.4 \%)$ & 75 & $(37.0 \%)$ \\
N1 & 27 & $(13.9 \%)$ & 27 & $(13.3 \%)$ \\
N2 & 97 & $(50.0 \%)$ & 85 & $(41.8 \%)$ \\
N3 & 0 & $(0.0 \%)$ & 1 & $(0.5 \%)$ \\
Nx & 0 & $(0.0 \%)$ & 4 & $(2.0 \%)$ \\
Missing & 9 & $(4.7 \%)$ & 11 & $(5.4 \%)$ \\
\hline
\end{tabular}

